\title{
The impact of air content on the durability of concrete under combined sulphate and freeze- thaw attack
}

\author{
Julia Marczewska ${ }^{1, *}$, and Wojciech Piasta ${ }^{1}$ \\ ${ }^{1}$ Department of Civil Engineering and Architecture, Kielce University of Technology, al.1000-lecia \\ PP 7, 25-314 Kielce, Poland
}

\begin{abstract}
The aim of the study was to determine the optimal air content in concretes subjected a combination of exposure conditions. Five series of concretes with different air contents were tested. The article reports the experimental results of the combined sulphate expansion and freeze-thaw attack in ordinary Portland cement concrete. Some of the concrete samples were immersed in a 5\% sodium sulphate solution for nine months, and then frozen in air and thawed in water. The resistance of concrete to plain freezing and thawing was also tested. In order to compare the degree of concrete damage in both environments, long-term linear deformations (expansion) and compressive strength of concretes were investigated. To explain the complex damaging process the air-void structure in concretes was investigated. The changes in concrete microstructure after storing in sodium sulphate solution were observed under the scanning electron microscope (SEM). The prior sulphate attack significantly accelerated the deterioration of non-air-entrained concrete and air-entrained concrete with low content of air voids. Optimal air entrainment will protect concrete from the harmful effects of the interaction of sulphate attack and freezethaw damage.
\end{abstract}

\section{Introduction}

In water structures, bridges, tunnels and foundations, simultaneous or alternate occurrence of frost damage and sulphate corrosion is frequent.

According to Powers [1], water freezes gradually. As the temperature decreases, the ice content in the capillary pores increases, and because the freezing water increases its volume by about $9 \%$, it is expelled from the capillaries. The amount of ice increases gradually with decreasing temperature and the length of time. The flow and thus the pressure increase with the increasing freezing rate and water quantity [2], causing swelling and then disruption in concrete.

In non-air entrained concrete, transport system for gas, water and solutions is provided by the w/c ratio-dependent capillary pores [3], the predominant factor affecting the frost durability of concrete. The deterioration rate of non-air entrained concrete depends to the

\footnotetext{
* Corresponding author: jmarczewska@tu.kielce.pl
} 
highest extent on the degree of pore saturation with water, which is mainly related to the sorption and permeability of concrete. Concrete containing large diameter pores has the highest permeability. Nevertheless, freezing of water in small diameter pores is the source of the highest stresses [4].

The pore system includes pores always present in the hardened cement paste (gel, capillary pores and pores of entrapped air [5]) and the air pores incorporated deliberately to enhance the resistance of concrete freeze-thaw damage. Considering the air entrainment characteristics, the freeze-thaw resistance of concrete can be estimated on the basis of the pore size distribution, the spacing ratio and the content of pores with a diameter smaller than $300 \mu \mathrm{m}$ [6]. In fact, the spectrum of pore sizes is continuous and the pores can occur in a wide range of sizes (from 0.02 to $1 \mathrm{~mm}$ [2]); they can also coalesce under increasing air content or form larger systems in cement pastes when air entrainment has not been perfect [7]. It thus seems reasonable to examine whether air entrainment and different air contents have a significant effect on the freeze-thaw damage rate in the case of concretes previously subjected to sulphate attack [8]. It should be remembered that sulphate attack products will precipitate, changing the microstructure of the concrete. The physical effects of sulphate attack and freeze-thaw cycle-related deterioration were investigated but in the range of nonair-entrained concretes $[9,10]$.

In recent years, the theory of sulphate expansion due to the growth of ettringite crystals and the accompanying crystallization pressure has gained importance as the most probable hypothesis for concrete swelling under the influence of external sulphate attack [11]. Some researchers have long pointed out that during the attack of the sulphate solution, expansion is not necessarily dependent on the amount of ettringite formed [12]. According to Scrivener $[13,14]$, expansion is not related to the amount of ettringite but depends on the sites in which ettringite crystallizes. The expansion is induced by an increase in size of ettringite crystals formed as a result of $\mathrm{Al}(\mathrm{OH})^{4-}, \mathrm{Ca}^{2+}$ and $\mathrm{SO}_{4}{ }^{2-}$ and $\mathrm{OH}^{-}$reaction in supersaturated solutions. The crystallization pressure can be transferred to the microstructure of the cement paste only where it meets the resistance, and this occurs in very small pores in the $\mathrm{C}-\mathrm{S}-\mathrm{H}$ phase at the monosulphate phase location. The precipitation of ettringite in very small pores restraining the growth of the crystals will cause mechanical pressure on the pore walls and the expansion of the paste microstructure, whereas the free, unrestrained growth of large ettringite crystals in large pores will not be the cause of expansion in the hardened cement paste. Scherer [11] shows that the crystallization pressure is inversely proportional to the size of pores in which the crystal grows. Thus, the crystals of ettringite growing in small pores of the order of tens of nanometres are probably the most significant factor in generating internal stresses leading to paste expansion during the attack.

There is, therefore, some similarity in the mechanisms of freeze-thaw damage and sulphate attack $[15,16]$. For either of them to occur, the capillary pores must be filled with water or solution and, above all, higher stresses will be exerted by the growth of ice or ettringite crystals in small-diameter pores.

\section{Experimental procedure}

\subsection{Aim and scope of the experiment}

The aim of this study was to investigate and evaluate the effects of the different air content on durability of concretes exposed to complex deterioration conditions.

Non-air entrained and air entrained concrete mixes with an air content of 3-4\%, 4-5\%, 6$7 \%$ and $8-9 \%$ were prepared according to the assumption of the experimental design. The 
air content was measured on freshly mixed concrete by pressure method. The bulk density and consistency were additionally determined. An optical microscope was used to examine the structure of the air pores in the hardened concretes. The samples were also tested for absorption and compressive strength at 28 days of curing in water. After prior sulphate attack the frost durability of concretes was tested and the plain frost durability of concretes for comparison. Scanning electron microscopy (SEM) was used to explain changes in the microstructure and deterioration rate in the air-entrained concretes.

\subsection{Materials}

Five series of concrete with Portland cement were prepared according to chemical composition shown in Table 1. The aggregate composition was prepared in accordance with [17]. Coarse basalt aggregate $(2-8,8-12 \mathrm{~mm})$ and natural quartz sand $(0-2 \mathrm{~mm})$ were used. Coarse aggregate sizes were limited by sieving grains over $12 \mathrm{~mm}$ due to non-standard specimen size. The aggregates volume fraction was the same in all mixes, with the following proportions:

- coarse basalt aggregate $2 / 8-33 \%$

- coarse basalt aggregate $8 / 12-33 \%$

- fine quartz aggregate $0 / 2-34 \%$

Table 1. Chemical and phase composition of Portland cement [\%].

\begin{tabular}{|c|c|c|c|c|c|c|c|c|c|}
\hline \multirow{3}{*}{ Cement } & \multicolumn{6}{|c|}{ Chemical composition } & \multirow[b]{2}{*}{$\mathrm{SO}_{3}$} & \multirow[b]{2}{*}{$\mathrm{Cl}^{-}$} & \multirow[b]{2}{*}{$\mathrm{Na}_{2} \mathrm{O}_{\mathrm{eq}}$} \\
\hline & $\mathrm{SiO}_{2}$ & $\mathrm{Al}_{2} \mathrm{O}_{3}$ & $\mathrm{Fe}_{2} \mathrm{O}_{3}$ & $\mathrm{CaO}$ & $\mathrm{CaO}_{\text {(wolne) }}$ & $\mathrm{MgO}$ & & & \\
\hline & 21.31 & 5.01 & 3.36 & 65.06 & 1.53 & 1.95 & 0.74 & 0.03 & 1.14 \\
\hline \multicolumn{10}{|c|}{ Phase composition } \\
\hline \multirow[t]{2}{*}{ CEM I } & & & $\mathrm{C}_{3} \mathrm{~S}$ & \multicolumn{2}{|c|}{$\mathrm{C}_{2} \mathrm{~S}$} & $\mathrm{C}_{3} \mathrm{~A}$ & \multicolumn{3}{|c|}{$\mathrm{C}_{4} \mathrm{AF}$} \\
\hline & & & 67.83 & \multicolumn{2}{|c|}{13.57} & 7.76 & & \multicolumn{2}{|c|}{11.70} \\
\hline
\end{tabular}

Tap water was used as batch water in accordance with PN-EN 206 [18]. The watercement ratio was 0.55 . Synthetic surfactants were used as an air entraining agent with a density of about $1.0 \mathrm{~g} / \mathrm{cm} 3$. Table 2 shows the composition of the concrete mixtures.

The amount of air entraining agent was varied to obtain the air contents compliant with the experimental design assumptions:

- 3.2\% air content (series designated as $\gamma 1$ ) - insufficiently air entrained concrete [18]

- $4.5 \%$ air content $(\gamma 2)$ - properly air entrained concrete (acc. to PN-EN 206)

$-6.5 \%$ air content $(\gamma 3)$ - properly air entrained concrete (acc. to PN-EN 206)

- 8.5\% air content $(\gamma 4)$ - air entrainment higher than the recommended limit [18]

The non-air entrained mix had the air content of $1.6 \%$ ( $\gamma 5$ - concrete).

Table 2. Composition of concrete mixes per $1 \mathrm{~m}^{3}$.

\begin{tabular}{|llllll|}
\hline \multicolumn{1}{c}{ Component } & \multicolumn{5}{c|}{ Content $\left[\mathrm{kg} / \mathrm{m}^{3}\right]$} \\
Coarse basalt aggregates 2-8 & $\gamma 1$ & $\gamma 2$ & $\gamma 3$ & $\gamma 4$ & $\gamma 5$ \\
\cline { 2 - 6 } Coarse basalt aggregates 8-12 & 655.6 & 655.6 & 655.6 & 655.6 & 655.6 \\
Quartz sand 0-2 & 655.6 & 655.6 & 655.6 & 655.6 & 655.6 \\
Cement & 695.2 & 695.2 & 695.2 & 695.2 & 695.2 \\
Water & 334 & 334 & 334 & 334 & 334 \\
Air entraining admixture & $185^{*}$ & $185^{*}$ & $185^{*}$ & $185^{*}$ & $185^{*}$ \\
\hline
\end{tabular}

* - mass of water in the non-air entrained concrete; total mass of water with the air entraining agent in the air entrained concrete mixes. 
Cubes with dimensions 100x100x100 mm were prepared from each mix for compressive strength testing and air voids system characterization. Beams with dimensions $60 \times 60 \times 350 \mathrm{~mm}$ were prepared for investigating longitudinal strains during freezing/thawing and sulphate attack. The samples were cured in water for 28 days in accordance with PN-EN 12390-2 [19]. Half of the samples were immersed in a 5\% sodium sulphate solution for nine months, and then frozen in air and thawed in water. In order to minimize the influence of uncontrolled factors, the samples were prepared while maintaining identical manufacturing technology (identical order of added ingredients, mixing time, mixing intensity, temperature, contact time of cement with water before measurements).

\section{Results}

The properties of fresh concrete mixes, non-air entrained and air entrained with different air content are summarized in Table 3. Table 4 shows the average values from the results of compressive strength and water absorption tests after 28 days of curing in water.

Table 3. Result for the freshly mixed concrete mixes.

\begin{tabular}{|cccc|}
\hline Concrete & Consistency, slump $[\mathrm{mm}]$ & Bulk density $\left[\mathrm{kg} / \mathrm{m}^{3}\right]$ & Air content $[\%]$ \\
\cline { 2 - 4 }$\gamma 1$ & 9 & 2493 & 3.2 \\
$\gamma 2$ & 15 & 2455 & 4.5 \\
$\gamma 3$ & 23 & 2413 & 6.5 \\
$\gamma 4$ & 130 & 2328 & 8.5 \\
$\gamma 5$ & 9 & 2516 & 1.6 \\
\hline
\end{tabular}

The incorporation of additional air through the use of air entraining admixture reduced the bulk density of the mixtures designated as $\gamma 1, \gamma 2, \gamma 3$ and $\gamma 4$ by 0.9, 2.4, 4.1 and 7.5\%, respectively. The air entrainment changed the consistency of the mixes, making them more fluid.

Table 4. Compressive strength and absorption at the age of 28 days.

\begin{tabular}{|lccccc|}
\hline Concrete & CEM I $\gamma 1$ & CEM I $\gamma 2$ & CEM I $\gamma 3$ & CEM I $\gamma 4$ & CEM I $\gamma 5$ \\
\cline { 2 - 6 } Absorption [\%] & 4.96 & 5.25 & 5.96 & 6.05 & 5.83 \\
Compressive & 52.1 & 49.6 & 43.0 & 36.6 & 55.2 \\
strength [MPa] & & & & & \\
\hline
\end{tabular}

The results of the compressive strength test clearly illustrate the reduction in concrete strength after the use of air entraining admixture in proportion to the amount of admixture used. Absorption values increased with increasing air content in the air entrained concrete mixes.

To further examine the concretes, the pore system of the air entrained concrete mixes was evaluated (Table 5). The porosity of the hardened concrete was characterized using an automatic image analysis system and a computer program on properly prepared polished concrete surfaces. The photographs from the optical microscope (Figure 1a, 1b, 1c) showed evident differences in the number and distribution of air pores in the concrete samples.

Examination of the pore system indicated an increase in the total air content in the hardened concrete, in the specific surface area of the pores and in the micropore content with increasing amount of admixture used and, consequently, with the increasing air content in the fresh concrete mix. At the same time the spacing factor decreased. The designed air content was achieved, as confirmed by both hardened concrete and concrete mix. 
Table 5. Air pore system in the hardened concrete.

\begin{tabular}{|lccccc|}
\hline Concrete & \multicolumn{3}{c}{ Air pore system in the hardened concrete } & \multicolumn{2}{c|}{$\begin{array}{l}\text { Air content in fresh } \\
\text { mixes }\end{array}$} \\
& $\mathrm{A}[\%]$ & $\alpha\left[\mathrm{mm}^{-1}\right]$ & $\mathrm{L}^{-}[\mathrm{mm}]$ & $\mathrm{A} 300[\%]$ & $\mathrm{Zp} \mathrm{[ \% ]}$ \\
\cline { 2 - 6 }$\gamma 1$ & 3.11 & 15.25 & 0.332 & 1.04 & 3.2 \\
$\gamma 2$ & 4.19 & 18.18 & 0.299 & 1.28 & 4.5 \\
$\gamma 3$ & 6.66 & 28.91 & 0.152 & 3.71 & 6.5 \\
$\gamma 4$ & 9.16 & 34.75 & 0.090 & 5.41 & 8.5 \\
\hline
\end{tabular}

a)

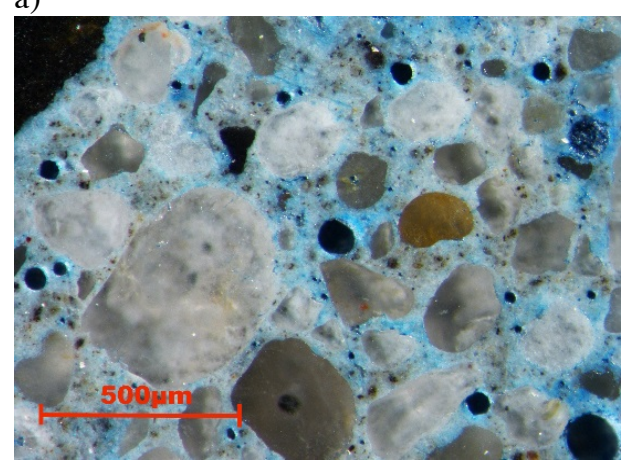

b)

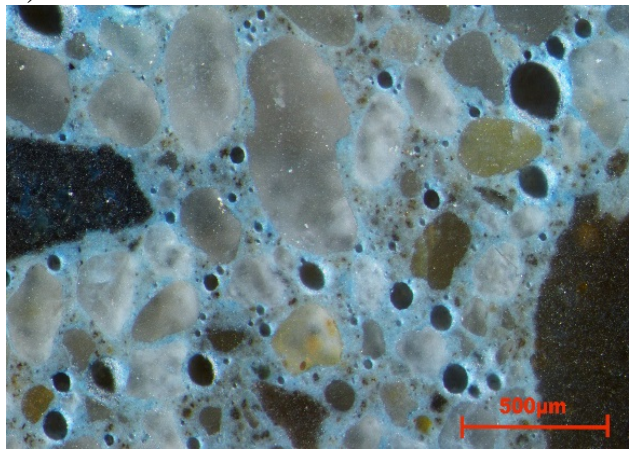

c)

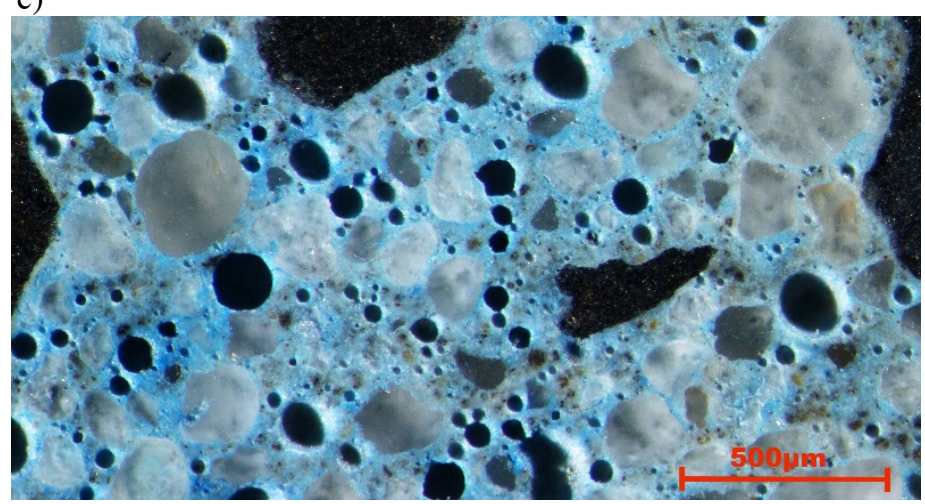

Fig. 1. View of the distribution of real air-pore structures on the surface of concrete samples a) $\gamma 2$ : A $=4.19 \% \mathrm{~L}^{-}=0.299$; b) $\gamma 3: \mathrm{A}=6.66 \% \mathrm{~L}^{-}=0.152$; c) $\gamma 4: \mathrm{A}=9.16 \% \mathrm{~L}^{-}=0.090$.

Irregular pores (indicative of entrapped air and capillary pores) were very rarely observed under optical microscope (Fig 1c). This can be associated with higher permeability of concretes for liquid and gaseous substances, which is related to the lowered resistance of concretes to chemical attack and cycles of freezing and thawing.

After performing the basic tests of the hardened concretes, the samples were divided into two groups. The first group included the samples subjected to 200 freeze-thaw cycles after nine months immersion in a solution of sodium sulphate were. The non-air entrained concrete showed a fast progressing increase in deformations as early as at 20 freeze-thaw cycles (Fig. 2). The final measurement of the non-air entrained samples after 200 cycles of freezing and thawing revealed the greatest deformation (over $2.5 \%$ ) of all the samples. The concrete with an air content of $3.11 \%$ reached low deformation - only $1.1 \%$ at the end of the test. The air entrained concretes of air content $4.19 \%$ and $6.66 \%$ had a linear deformation of about $0.6 \%$ after about 9 months immersion in the sodium sulphate 
solution, while during 200 freeze-thaw cycles this value showed a negligible increase and at the end of the test they showed the smallest deformation of $0.8 \%$. The concrete with the highest air content $(\gamma 4)$ had the final linear deformation $(2.1 \%$ ) under complex deterioration conditions (Fig. 2) similar to that of the non-air entrained concrete.



Fig. 2. Deformation of concretes subjected to $\mathrm{Na}_{2} \mathrm{SO}_{4}$ solution and then freeze-thaw cycles.

The other concrete samples were only subjected to cyclic freezing and thawing process. After 300 cycles, the non-air entrained concrete samples and those with the highest air content showed the highest and similar values of linear deformation. It is interesting that the concrete with $9.16 \%$ air content showed the highest linear deformation $(1.4 \%)$, higher than that of the non-air entrained concrete (Fig. 3). Throughout the test period, i.e., after 300 freeze-thaw cycles, the linear deformations in concretes with 4.19 and $6.66 \%$ air content did not exceed $0.2 \%$, while the deformation in concrete containing $3.11 \%$ of air reached $0.4 \%$ in the final stage.

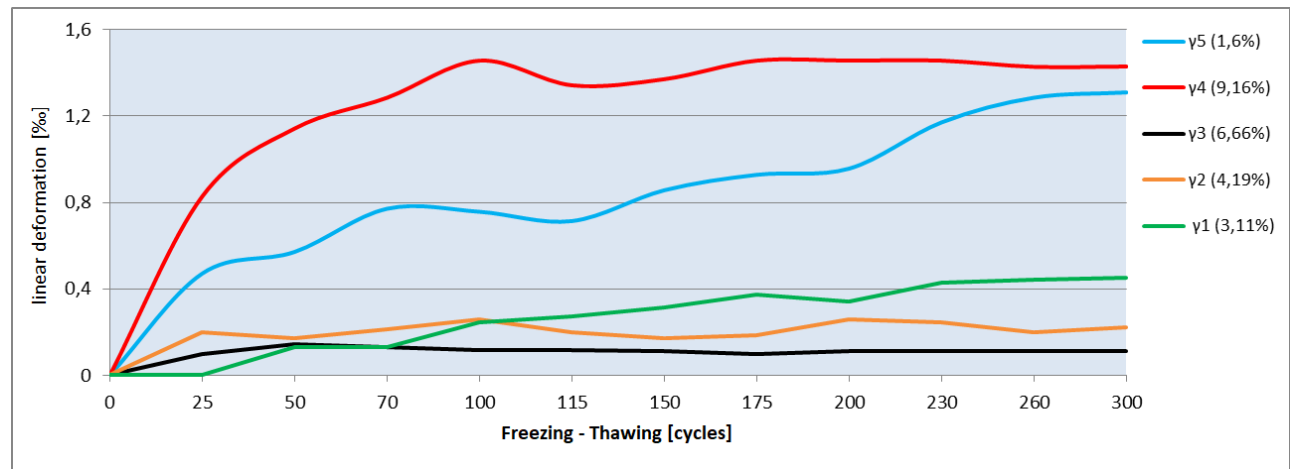

Fig. 3. Linear deformation of concretes after freeze-thaw cycles.

Compressive strength is given as a percentage of the 28-day strength for each concrete. All concretes subjected to the combined attack showed from 8 to $25 \%$ higher compressive strength measured after 9 months immersion in $\mathrm{Na}_{2} \mathrm{SO}_{4}$ solution in relation to the 28-day strength (Fig. 4). After this period, a drop in the strength during 200 freezing cycles was observed. In contrast, the concretes subjected only to freezing and thawing showed nothing but increase in the strength at the end of the test. 

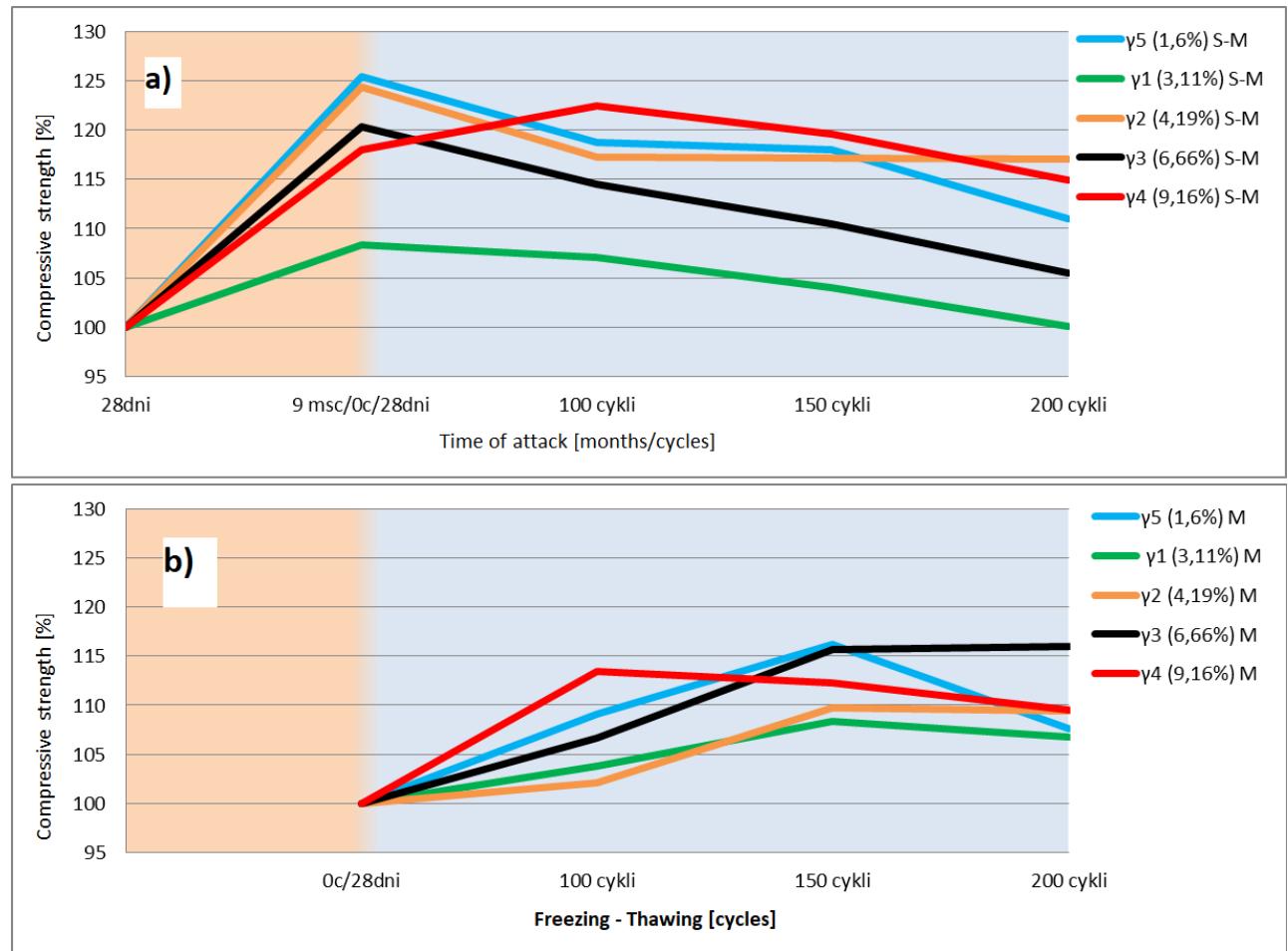

Fig. 4. Strength for the concretes: a) after 9 months of sulphate attack and after freeze-thaw cycles, b) frozen and thawed, expressed as percentage at 28 days for each concrete mix.

The air pores of the concretes (Fig. 5) were filled with ettringite crystals formed in the zone of active sulphate corrosion, i.e., at a distance of up to $1.5 \mathrm{~mm}$ from the surface of the concrete sample. The degree of pore filling, however, was dependent on the amount of air entrainment.

a)

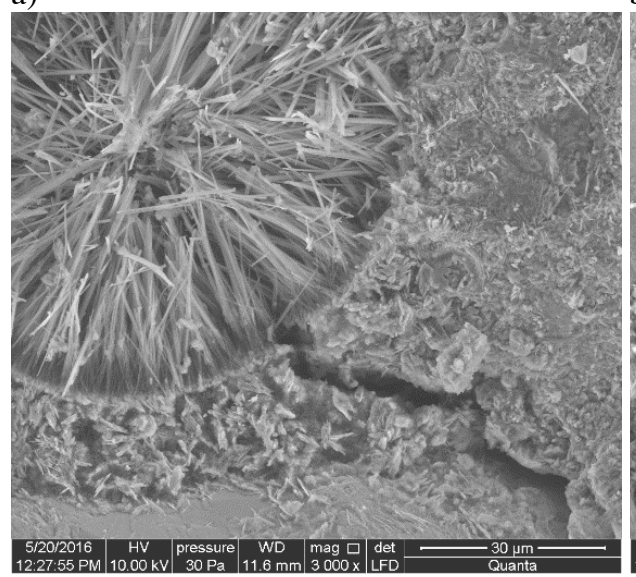

b)

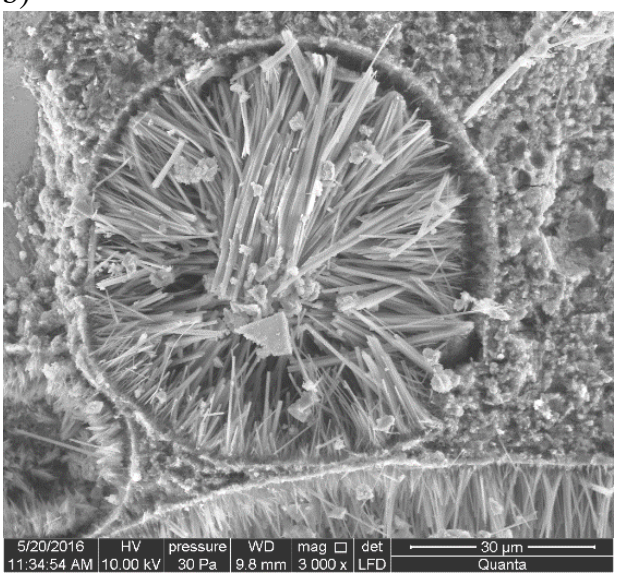

Fig. 5. SEM images of the microstructure of concretes after 9 months of immersion in the sodium sulphate solution before being subjected to freeze-thaw cycles a) concrete with a $3.11 \%$ air content; b) concrete with a $9.16 \%$ air content. 


\section{Discussion and conclusions}

The best frost resistance evaluated in experimental studies was found in concretes with an air content of $4.19 \%$ and $6.66 \%$. Prior sulphate attack reduced their freeze-thaw resistance only slightly. The performance of other air entrained concretes $(3.11 \%$ and $9.16 \%$ air content) deteriorated considerably and was similar to that of non-air entrained concretes. In order to explain that behaviour, SEM was employed for microstructural observations of concrete, with particular attention paid to the air voids. Figures 5a) and 5b) show the air voids filled with ettringite crystals. The largest degree of filling was found in the pores with a diameter smaller than $150 \mu \mathrm{m}$. It can therefore be assumed that the lower resistance of air entrained concretes previously subjected to sulphate attack was caused by sulphate attack products filling a portion of the pore volume. The resistance to freezing and thawing of non-air-entrained concretes, which were previously affected by the $\mathrm{Na}_{2} \mathrm{SO}_{4}$ solution, declined noticeably. The properly air entrained concretes $(4.19 \%$ and $6.66 \%)$ did not show major deformations during the initial sulphate attack and subsequent freeze-thaw cycles. The combined attack, however, led to a slightly accelerated strength reduction as compared to the effects of freeze-thaw cycles alone.

The incorporation of 4.19 and $6.66 \%$ air was considered optimal for maintaining durability under freeze-thaw damage and combined sulphate attack-freeze-thaw cycles conditions. The use of too high air content was found to reduce the durability of concrete.

\section{References}

1. T. Powers, Highway Research Board, PCA Bulletin 29, 184-211 (1949)

2. W. Kurdowski, Chemia cementu i betonu, (PWN, Warszawa, 2010)

3. I. Soroka, Portland Cement Paste and Concrete, 88 (Macmillan, London, UK, 1979)

4. Z. Rusin, Technologia betonów mrozoodpornych (Polski Cement, Kraków 2002)

5. P.K. Mehta, P.J. Monteiro, Concrete structure, properties and materials, (PrenticeHall, Inc., Englewood Cliff, New Jersey, Second Edition, 1993)

6. P.W. Brown, D. Shi, J. Skalny, Material Science of Concrete II, 83-110 (1991)

7. J. Wawrzeńczyk, W. Kozak, Constr. Build. Mat. 112, 360-365 (2016)

8. W. Piasta, J. Marczewska, M. Jaworska, Procedia Eng. 108, 5562 (2015)

9. L. Jiang, D. Niu, L. Yuan, Q. Fei, Cold Reg. Sci. Technol. 112, 112-117 (2015)

10. D. Wang, X. Zhou, Y. Meng, Z. Chen, Constr. Build. Mater. 147, 398-406 (2017)

11. G.W. Scherer, Cem. Concr. Res. 29(8), 1347 - 1358 (1999)

12. P.W. Brown, H.F.W. Taylor, Sulfate Attack Mechanisms (Am. Ceram. Soc. 1999)

13. C. Yu, W. Sun, K. Scrivener, Cem. Concr. Res. 43, 105-111 (2013)

14. W. Kunther, B. Lothenbach, K. Scrivener, Cem. Concr. Res. 46, 23-29 (2013)

15. D. Niu, L. Jiang, Q. Fei, Jour. Wuhan Univ. Tech. Mater. Sci. Ed. 28(6), 1172-1176 (2013)

16. H. Yang, X. Shen, M. Rao, X. Li, X. Wang, Adv. Mater. Sci. Eng 2015 (2015)

17. PN-EN $12620+\mathrm{A} 1(2010)$

18. PN-EN 206 (2014-04)

19. PN-EN 12390-2 (2011) 